\title{
Legibilidade de revistas eletrônicas de divulgação científica
}

\author{
Mônica Macedo-Rouet \\ Pesquisadora de pós-doutorado, U niversité Lyon 1 (França); \\ pesquisadora associada do Laboratório de Estudos A vançados em \\ Jornalismo (Labjor), Universidade de Campinas, e professora \\ licenciada da U niversidade M etodista de São Paulo. \\ E-mail: mmaced099@yahoo.com.br
}

\begin{abstract}
Resumo
Examina a utilização que fazem revistas de divulgação científica das tecnologias hipermídia. Em uma série de dois estudos, analisamos a argumentação e as condições de legibilidade de um conjunto de textos e hipertextos de seis revistas internacionais e avaliamos a compreensão de um hipertexto de divulgação científica através de um estudo experimental de leitura. Os resultados mostram que as revistas não levam em conta recomendações da pesquisa em ergonomia da hipermídia e que os hipertextos podem induzir mudanças de argumentação. Nosso estudo experimental mostrou efeitos significativos de redução da compreensão e de aumento da percepção carga cognitiva na condição de leitura do hipertexto. Concluimos que a legibilidade das revistas eletrônicas de divulgação científica é, no estado atual da arte, insatisfatória, mas pode ser melhorada, caso as revistas sigam critérios oriundos da pesquisa experimental sobre o tema. Os resultados desta pesquisa podem orientar conceptores de revistas de divulgação científica em suas decisões sobre a elaboração de versões on-line.
\end{abstract}

\section{Palavras-chave}

Revista de divulgação científica; Tecnologia hipermídia; Hipertexto.

\section{Readability of electronic journals of scientific dissemination}

\begin{abstract}
This paper examines the uses of hypermedia technologies by popular science magazines, in the light of the potential implied by these technologies. In a series of two studies, we investigated the argumentation and readability of texts and hypertexts from six popular science magazines and we conducted an experimental study with one of the texts from the corpus. Results show that science magazines do not fully apply recommendations from research in ergonomics of hypermedia, and hypertext conducted to lower comprehension scores and higher perception of cognitive load. Conclusions suggest that popular science magazine's readability is currently very poor, but it could be improved by the application of some criteria from research in ergonomics. Our results may guide online authors in the development of online versions of traditional science magazines.
\end{abstract}

\section{Keywords}

Journals of scientific dissemination; Hypermedia technology; Hypertext.
As tecnologias hipermídia têm sido apontadas como uma poderosa ferramenta para 0 desenvolvimento de novos modelos de divulgação científica (Bauer, 1996; Eveland \& Dunwoody, 2001; Peterson, 2001; Trench, 2000). Potencialmente, elas facilitam 0 acesso a informações da pesquisa científica pelo grande público (Peterson, 2001), estimulam a multiplicação das fontes de informação (T rench, 2000), diminuem as restrições de espaço e os custos de distribuição das revistas de divulgação científica (Eveland \& Dunwoody, 2001) e incentivam a formação de grupos de discussão a distância. A utilização dessas tecnologias poderia favorecer o desenvolvimento de um modelo de divulgação científica mais aberto à discussão e ao debate, tal como o preconizam diversos autores (Friedman et alii, 1999; H ouse of the Lords, 2000; M iller, 2001). Entretanto, sabemos que 0 uso de tais tecnologias cria também dificuldades para certos usuários, sob certas condições (Dillon \& G abard, 1998; Rouet, 2001). Por exemplo, um efeito negativo bem conhecido da leitura em hipertexto éa desorientação (Dillon \& G abard, 1998). Diante disso, que conseqüên cias existem para a divulgação de informaçãoes científicas e tecnológicas? Como os potenciais e as limitações da tecnologia afetam a divulgação?

Comecemos pelos potenciais. Trench (2000) sugere que a Internet e as tecnologias hipermídia criam um "novo espaço" para o jornalismo científico, em que 0 jornalista deve atuar como um "guia" do leitor através de múltiplas fontes de informação. Desprovido de sua função de gatekeeper, já que as fontes podem difundir elas mesmas suas informações por meio de seus sites, o jornalista científico da W orld W ide W eb tem de deixar de ser essencialmente um transmissor de informações para tornar-se um intérprete e apresentador competente das diversas fontes disponíveis sobre um mesmo assunto. Trumbo et alii (2001) mostram que jornalistas científicos são de fato grandes usuários do email e da W eb, que consideram como ferramentas eficientes de reportagem. $M$ as verificam também que os maiores e mais experientes usuários são os que mais desconfiam dos resultados obtidos. Q uanto ao papel da Internet nas estratégias atuais de comunicação da ciência, Bauer (1996) afirma que ele é fundamental, sendo uma das marcas do "ciclo 


\section{Legibilidade de revistas eletrônicas de divulgação científica}

de expansão" da divulgação científica que vivemos atualmente.

Com o hipertexto, é possível associar eletronicamente diferentes documentos e criar modalidades de consulta mais "flexíveis", por meio de menus e outras formas de links não-tineares. Para alguns autores, essa característica do hipertexto corresponderia à maior liberdade de 0 indivíduo escolher seus próprios percursos de navegação, estimulando a leitura multilinear, a possibilidade de compreensão mais intuitiva do conteúdo a partir da navegação por links e ao engendramento de autor e leitor (Bal pe et alii, 1996; Bolter, 1991; Landow, 1997; Palácios, 1998). Trata-se de um potencial que, desde as origens do hipertexto, foi colocado em relevo. V annevar Bush (1945) e Douglas Engelbart (1963), precursores do hipertexto, natureza associativa e criativa da mente humana.

Theodor Nelson (1981), criador do termo "hypertext", imaginava que o hipertexto seria uma forma muito mais eficiente (que o texto impresso) de criar conexões entre documentos e estimular a criatividade. 0 "hipertexto ideal" de N elson deveria permitir ao leitor acessar, a partir de um "ambiente de trabalho interativo", uma biblioteca de referência, fazer anotações, selecionar trechos que mais lhe interessem, gravá-los em sua "biblioteca pessoal", criar links entre documentos antes não relacionados etc. Podemos, entretanto, perceber que tal descrição corresponde ao trabalho de escrita e leitura de um pesquisador, o qual, tendo de antemão um bom conhecimento do universo no qual está "navegando", é capaz de fazer as seleções e perguntas apropriadas ao banco de dados, segundo o problema que lhe interessa resolver. Porém, corresponderiam as habilidades mais gerais de leitores de hipertextos àquelas que são descritas por $\mathrm{N}$ elson? $\mathrm{N}$ ão é o que parecem indicar pesquisas recentes.

Pesquisas experimentais feitas com usuários de hipertextos mostram que a "liberdade" de que estes dispõem para definir seus próprios "caminhos de escrita e leitura" não representa necessariamente uma vantagem em relação ao texto linear impresso (C harney, 1991; Chen \& Rada, 1996; Dillon \& Gabbard, 1998; Eveland \& Dunwoody, 2001; Tewksbury \& Althaus, 2001). Pelo contrário, em geral, a estrutura complexa do hipertexto representa uma dificuldade, demandando do leitor conhecimentos metatextuais específicos (por exemplo, uso de index e sumário, capacidade de localização de uma informação no texto, compreensão da estrutura de títulos e intertítulos) (Rouet, 2001). A eficácia do hipertexto depende fundamentalmente do domínio funcional propunham que um tal sistema seria capaz de imitar a

(metacognitivo) que os usuários possuem da tecnologia e da tarefa a ser desempenhada, além de seus conhecimentos prévios sobre 0 assunto tratado no texto (Dillon \& Gabbard, 1998). Para usuários pouco experientes, a probabilidade de desorientação e de sobrecarga cognitiva com a leitura de um hipertexto é grande, fazendo com que os leitores simplesmente "passeiem" (scan) pelo texto, sem que efetivamente 0 leiam e compreendam. 0 pressuposto de que o domínio da tecnologia se dá de maneira "natural" ou "muito rápida", como afirma Lévy (1997), não encontra, pois, qualquer fundamento empírico. Por outro lado, o balanço das pesquisas experimentais sobre hipermídia não é totalmente negativo, havendo situações em que 0 hipertexto revela-se eficaz para a compreen são (cf. Chen \& Rada, 1996).

\section{Q uestão e hipóteses da pesquisa}

Considerando que o hipertexto apresenta, simultaneamente, potenciais e limitações, colocamo-nos a seguinte questão de pesquisa:

Por facilitar, potencialmente, 0 acesso às fontes de informação, multiplicar o número de documentos que compõem um texto, bem como permitir modalidades de leitura não-linear, os hipertextos de revistas de divulgação científica promoveriam o caráter "intertextual" de um texto de divulgação científica, ou seja, facilitariam e estimulariam a leitura de textos múltiplos?

Duas hipóteses principais foram investigadas:

1a) A disposição dos textos de revistas de divulgação científica em hipertexto altera características argumentativas e condições de legibilidade, criando problemas de intertextualidade.

Esta hipótese repousa sobre a constatação de que, em todo meio, forma e conteúdo interagem. O ra, a "forma" do meio hipertextual difere largamente da dos textos impressos: tamanho das janelas de leitura, modo de passagem de uma página a outra e também mudanças nas regras que regem 0 acesso à informação (principalmente pela supressão da inscrição física e espacial dos documentos e das páginas em proveito de sua "indexação" lógica nas redes de links hipertextuais). Acreditamos que essas transformações induzem uma evolução da retórica das matérias de divulgação científica, sobretudo mudando as regras de visibilidade/ legibilidade das diferentes fontes textuais e documentais no espaço de leitura que constitui a tela do computador. 


\section{Mônica M acedo-Rouet}

2a) 0 hipertexto estimula a criação de matérias de divulgação científica mais elaboradas, incluindo documentos não reproduzidos no impresso.

Esta hipótese, complementar em relação à primeira, deriva das novas "representações dos conhecimentos" permitidas pelo meio eletrônico. 0 hipertexto autoriza uma estruturação não-linear das matérias multidocumentais, tornando potencialmente visíveis as redes argumentativas que perpassam essas matérias. Ele permite também a representação de fenômenos complexos, por meio de gráficos e animações, sem equivalente no suporte impresso. Ele permite, enfim, a inclusão de referências "exofóricas" que podem inserir o conteúdo informativo de uma matéria no conjunto de seu contexto, independentemente da inscrição física das fontes. Examinamos o uso que as revistas de divulgação fazem dessas novas ferramentas, assim como sua apropriação pelos leitores de hipertextos.

Para investigar tais hipóteses, selecionamos seis revistas de divulgação científica cuja versão on-line reproduzisse integralmente o conteúdo da versão impressa e desenvolvemos dois estudos complementares*. 0 primeiro consistiu em uma comparação das versões impressa e on-line (hipertexto) de seis matérias de capa dessas revistas (uma por revista). Seu objetivo era avaliar a legibilidade dos hipertextos e verificar se mudanças argumentativas ocorriam em relação à versão impressa. o segundo estudo consistiu em uma pesquisa experimental de leitura de uma das matérias do corpus. Seu objetivo era avaliar a compreensão da versão impressa e da versão hipertextual por leitores da matéria. Cada estudo seguiu uma metodologia específica, que será apresentada juntamente com seus resultados, em duas seções, a seguir. $\mathrm{N}$ as conclusões, sugerimos uma interpretação global dos resultados.

\section{ESTU D 01}

O corpus deste estudo compõe-se de seis matérias: "Safeguarding our water" (Scientific A merican, fev/ 2001); "O ndes, quelles raisons d'avoir peur?" (La Recherche, dez/2000); "A pílula da discórdia" (Superinteressante, abr/ 2001); "C éticos, os inquisidores da razão" (G alileu, mar/2001); "Retrouvez votreancêtre C roM agnon" (Sciences et A venir, abr/ 2001); "M arijuana, a safe

\footnotetext{
* A escolha das revistas se fez com base em uma análise de conteúdo de 34 títulos, em que estabelecemos uma categorização dessas publicações por tipo de público e pela quantidade de conteúdo reproduzido + complementos, na versão on-line. Selecionamos apenas revistas com sites "consistentes", que não fossem meros resumos ou fichas técnicas das publicações.
}

high?" (N ew Scientist, 21/ fev/ 1998)*. Elas haviam sido reproduzidas nas versões on-line de suas respectivas revistas e eram, portanto, passíveis de serem lidas na forma de hipertexto por usuários que, entrando no site, se interessassem pelo tema. Comparamos as versões impressa e hipertexto e investigamos as condições de legibilidade e argumentação dessas matérias.

\section{M etodologia}

Levamos em conta critérios de legibilidade utilizados na pesquisa sobre compreensão e ergonomia de documentos hipermídia. Elaboramos um roteiro das principais recomendações sobre a legibilidade de hipertextos, com base em diversos autores, majoritariamente a partir de resultados de pesquisas experimentais ( $C$ aro \& Bétrancourt, 1998; N ielsen, 2000; Gleaves, 1998; DeeLucas, 1996; V an O ostendorp \& V an N imwegen, 1998; Schnotz, W., 2001; Eveland \& Dunwoody, 1998). Essas recomendações abarcam aspectos ergonômicos (por exemplo, "utilizar alto contraste"), metatextuais (por exemplo, "permitir ao leitor se reportar facilmente ao menu de navegação"), de funcionalidades do suporte (por exemplo, "fornecer a possibilidade de fazer anotações sobre o conteúdo do texto") e de identificação das fontes (por exemplo, "categorizar os links relativos a diversas fontes de informação"). Ao todo, 34 recomendações faziam parte do roteiro.

A lém disso, fizemos uma análise argumentativa das matérias, cujo objetivo era oferecer uma interpretação dos textos e detectar possíveis mudanças argumentativas na passagem do texto ao hipertexto. Identificamos 0 argumento principal e os argumentos secundários de cada matéria, bem como alguns recursos lingüísticos e estilísticos utilizados. Procuramos ref letir como os diversos documentos que compõem essas matérias ref letiam os argumentos, tanto pelo seu conteúdo, quanto pela forma como eram organizados dentro da matéria. Embora não tenhamos quantificado este aspecto, procedemos da mesma maneira para as seis matérias, utilizan do um roteiro de análise argumentativa baseado nos critérios de Breton (1996), V ignaux (1999) e Koch (1996).

\footnotetext{
Tais matérias são constituídas por múltiplos documentos: textos (reportagens, comentários, entrevistas, artigos etc.), tabelas, infográficos, fotografias, entre outros. Trata-se do que chamamos "textos multidocumentais".
} 
Resultados

A comparação das versões impressa e hipertextual mostra, primeiramente, que o conteúdo dos hipertextos não é exatamente idêntico ao dos textos impressos. A tabela 1 mostra o número de documentos presentes em cada uma das versões e indica se o hipertexto inclui complementos à versão impressa. Consideramos, como complementos, textos adicionais referenciados por links, outros documentos adicionais (fotos, infográficos etc.), links para grupos de discussão do tema, chat, glossário, áudio, vídeo, e-mail para contato, mecanismo de busca em arquivo.

A maior parte das matérias apresenta menos documentos na versão hipertexto do que na versão impressa. Essa diminuição corresponde, em grande parte, à eliminação de fotos e ilustrações na versão on-line. É 0 caso, por exemplo, da matéria de Sciences et A venir sobre "genealogia genética", em que notamos uma drástica diminuição do número de documentos no hipertexto. $\mathrm{N}$ a verdade, 38 dos 68 documentos da versão impressa são fotos, que no hipertexto foram suprimidas, com exceção de uma única ilustração (que, curiosamente, faz referência a um argumento marginal da matéria, pois trata do papel da genealogia genética no caso particular de grupos cuja origem se perdeu no tempo). A penas uma matéria, "M arijuana, a safe high?" (N ew Scientist), possui mais documentos na versão hipertexto. Trata-se de notícias publicadas ulteriormente pela revista sobre 0 assunto, além de dois textos ("A erosols: the future of the spliff?" e "Is there such a thing as a cannabis addict?") não publicados na versão impressa, provavelmente por restrições de espaço. $\mathrm{N}$ as demais revistas, são reproduzidos na versão hipertexto os textos principais da matéria (texto de abertura dos editores, artigos e reportagens) e algumas fotos e infográficos.
A tabela 2 mostra o número de recomendações, por categoria, aplicadas nas versões hipertextuais das matérias. As cores das colunas representam as categorias de legibilidade utilizadas (do mais escuro ao mais claro): elementos metatextuais; el ementos ergonômicos, funcionalidades do suporte e fontes de informação. As iniciais das colunas indicam os componentes específicos de cada categoria.

Vemos que, em todas as versões hipertexto das matérias, menos da metade das recomendações de legibilidade são aplicadas. No que se refere às funcional idades do suporte, nenhum dos hipertextos atende às recomendações. Estas referem-se a possibilidades de manipulação do suporte, como criar referências cruzadas e fazer anotações sobre o conteúdo, as quais, segundo G leaves (1998), têm efeitos sobre a compreensão e o aprendizado. Tal como um livro ou uma revista, os hipertextos deveriam permitir que o leitor manipule 0 texto (sublinhe, anote, folheie etc.), o que não é o caso dos hipertextos que analisamos.

Entretanto, aplica-se a maioria das recomendações de ergonomia. A o todo, vemos que, das 17 recomen dações, obtêm-se os seguintes resultados: 11 (Scientific A merican), 


\section{Mônica M acedo-Rouet}

9 (La Recherche), 8 (Superinteressante), 12 (G alileu), 9 (Sciences et A venir) el1 ( $\mathrm{N}$ ew Scientist). Todos os hipertextos seguem, por exemplo, as recomendações de utilizar alto contraste (texto preto sobre fundo branco), justificar 0 texto à esquerda e utilizar espaço em branco para separar parágrafos (em vez de tabulação), o que indica que certos padrões de formatação começam a ser seguidos por todas as publicações. Ainda assim, há recomendações ergonômicas semelhantes, como utilizar tamanho de fonte 12 (ou maior) para textos e utilizar baixa densidade informativa, que não são seguidas por todas as revistas. É o caso de La Recherche e N ew Scientist, cujos textos utilizam fonte 10 ou menor (segundo o tipo de texto), a despeito do fato de a versão on-line de $\mathrm{N}$ ew Scientist ser mais desenvolvida que a de La Recherche em termos de complementos (sobretudo textos) e serviços oferecidos.

Q uanto a outras recomendações ergonômicas, como utilizar janelas pop up para definições, explicações e exemplos (e não para informações essenciais), a situação é variável, pois há publicações que nunca utilizam 0 recurso de pop up, portanto a recomendação não se aplica. É o caso de Galileu, que optou por apresentar todos os documentos, mesmo textos complementares, na mesma janela do navegador. Os textos complementares, que aparecem em box na versão impressa, são acessados por um menu (lista de textos) ao final de cada página, e nunca há dois textos aparecendo simultaneamente na tela. Em relação à recomendação estabelecida não há incompatibilidade, pois simplesmente o recurso de pop up não é utilizado. 0 contrário acontece no hipertexto de Superinteressante, em que os documentos complementares, embora também sejam acionados a partir de um menu, aparecem todos em janelas pop up. U m desses documentos é um infográfico que, na versão hipertexto, recebe uma animação (em Flash) e é apresentado em tamanho reduzido (tamanho do pop up), de forma que os textos da figura tornam-se praticamente ilegíveis, a menos que 0 usuário acione um zoom, a partir do botão direito de seu mouse (caso utilize um computador PC). O utros documentos podem ser abertos simultaneamente através do recurso pop up, sobrepondo-se ao texto principal. A não-aplicação da recomendação, neste caso, poderia prejudicar globalmente a legibilidade deste hipertexto.

$\mathrm{Na}$ categoria dos elementos metatextuais e da identificação das fontes de informação, como no total, menos da metade das recomendações é seguida pelas revistas. N enhum dos hipertextos segue a recomendação de fornecer links de uma página à seguinte, o que permitiria uma leitura linear e reduziria o risco de desorientação para o leitor, como mostram Eveland \& Dunwoody (1998; 2001). Além disso, os menus contêm pouca ou nenhuma informação sobre os documentos a que fazem referência, tornando difícil visualizar a hierarquia interna à matéria (texto principal, textos complementares, exemplos, tabelas ilustrativas etc.). N o hipertexto de Sciences et A venir, por exemplo, 15 textos são listados pelo título, sem ordem explícita, correspondendo vagamente à ordem em que aparecem nas páginas da revista impressa (o que não é exato, pois na versão impressa a maioria dos textos aparece concomitantemente ao texto principal, que, por sua vez, distribui-se em diversas páginas). 0 único elemento indicando que se trata de um conjunto de textos da mesma matéria é o título geral, "La nouvelle généalogie ADN". Esta informação, no entanto, não representa as diferenças entre tamanho e tipos de texto (reportagem principal, textos de apoio etc.).

O bservamos também que a escassez de informações nos menus pode omitir aspectos argumentativos que na versão impressa são mais facilmente percebidos devido à utilização de recursos iconográficos, subtítulos e outros. Por exemplo, a utilização de argumentos de autoridade, que aparece claramente em títulos como " $\mathrm{M}$ arcel $\mathrm{O}$ tte: on ne voit pas tout dans les gènes" (no menu do hipertexto deSciences et A venir), mas não em "Sur la piste des Eve européennes" (no mesmo menu), embora ambos se apóiem na palavra de dois especialistas (o historiador $\mathrm{M}$ arcel $\mathrm{O}$ tte, no primeiro caso, e o geneticista Bryan Sykes, no segundo). Entretanto, em todas as matérias analisadas há operações de discurso em jogo (seleções, determinações e julgamentos) e utilização de recursos lingüísticos e estilísticos específicos (principalmente argumentos de autoridade, mas também analogias e exemplos), que não se modificam na passagem do texto ao hipertexto, visto que os textos são os mesmos, embora a falta de revisão crie problemas de coesão em algumas matérias (por exemplo, a referência textual a documentos que foram suprimidos na versão hipertexto, como acontece no hipertexto de La Recherche).

0 utro item dos menus hipertextuais que implica possíveis mudanças argumentativas é a utilização do termo "introdução" para nomear os textos de apresentação dos editores, como o fazem La Recherche eScientific American. $O$ u, então, a utilização do título geral da matéria introduzindo o texto dos editores (por exemplo, "M arijuana Special Report"), enquanto os outros textos são introduzidos por títulos específicos, como o faz $\mathrm{N}$ ew Scientist. Os textos de apresentação dos editores são, no entanto, sínteses do que é dito no conjunto da matéria, além de conter a interpretação da redação sobre 0 


\section{Legibilidade de revistas eletrônicas de divulgação científica}

assunto. Eles têm papel argumentativo para além de uma simples "introdução". Na versão impressa, este termo não é utilizado; no entanto, nós o encontramos nos hipertextos.

Algumas recomendações não se aplicam a todos os hipertextos, pois o recurso a que elas se referem não é utilizado. Seu número está indicado na coluna "NSA" da tabela 2. Embora esses casos existam em todos os hipertextos, eles são pontuais e não mudam significativamente os resultados globais de legibilidade.

\section{Discussão}

Os resultados da análise mostram que as condições de legibilidade dos hipertextos de matérias de revistas de divulgação científica são, em geral, insatisfatórias. Os principais problemas estão localizados na estruturação dos menus desses hipertextos, que não representam apropriadamente as características dos documentos (ausência de autor, data, tamanho e conteúdo do texto etc.), nem as relações entre eles (textos principais, documentos secundários, tabelas, gráficos etc.). Com isso, torna-se difícil perceber forma, extensão e número de documentos da matéria.

A pesar de os hipertextos analisados não apresentarem muitos caminhos de navegação, faltam elementos de orientação de leitura recomendados, como ícones para passar à página seguinte. A falta de informações metatextuais sobre os links torna difícil saber o que há por trás deles e pode dificultar a navegação, posto que 0 leitor tem de fazer inferências a partir de poucos e fracos indícios. Adicionalmente, a inexistência de ferramentas que permitam a manipulação do texto, como a possibilidade de fazer anotações, de criar referências, de imprimir, entre outras, torna difícil compensar os problemas de navegação mencionados.

Além disso, é pouco provável que o hipertexto leve a interpretações radicalmente diferentes dos argumentos veiculados nas matérias. Recursos como a ironia, analogias, argumentos de autoridade, que são freqüentes nessas matérias e importantes para a sua interpretação, não deixam de existir nem se alteram totalmente no hipertexto. Porém, o hipertexto pode levar a dificuldades de leitura e compreensão dos argumentos devido a más condições de legibilidade. Com isso, a forma de organização e apresentação dos documentos, que tem papel de sustentação dos argumentos do texto, não cumpre com a sua função nas versões hipertextuais, podendo mesmo prejudicar a argumentação. A intertextualidade se viu prejudicada nos hipertextos das revistas de divulgação científica analisadas.

\section{ESTU D 02}

Os resultados do estudo 1 apontaram diversos problemas de legibilidade do hipertexto. Pareceu-nos, então, indispensável fazer um estudo experimental de leitura para verificar se estes problemas levariam os leitores a interpretações inadequadas e/ ou a dificuldades de compreensão do material. Para isso, valemo-nos da metodologia de pesquisa oriunda da psicologia cognitiva (cf. Britt et alii, 1996; Dee Lucas, 1996), que é também usada nas ciências da informação e da comunicação (cf. Eveland \& Dunwoody, 2001)*.

\section{M etodologia}

A experiência focalizou a matéria "A pílula da discórdia" (Superinteressante, abr./ 2001) e estruturou-se da seguinte forma:

Participantes: 59 estudantes do quarto ano do curso de graduação em jornalismo. I dade, grau de escolaridade e categoria socioeconômica desses estudantes correspondem às do público-alvo de Superinteressante.

M aterial: versões impressa (papel) e hipertexto da matéria "A pílula da discórdia". O s leitores da versão papel usaram, cada um, um exemplar da revista impressa. Eles realizaram a leitura em uma sala de aula comum. Os leitores da versão hipertexto usaram, cada um, um computador PC, Pentium 166, tela 14". 0 conteúdo da matéria era idêntico nas duas versões.

Préteste: 0 material de préteste (questionário aplicado antes da leitura) se compunha de 16 questões destinadas a avaliar as seguintes dimensões :

a) experiência com a tecnologia (seis questões, por exemplo, sobre a freqüência de utilização da Internet) ;

b) a regularidade de consulta à revista;

c) o conhecimento da matéria;

d) os conhecimentos iniciais do tema (sete questões de múltipla escolha sobre informações presentes na matéria);

e) a opinião sobre o aborto. Esta questão não foi diretamente utilizada para a composição dos grupos. Seu objetivo era controlar eventuais mudanças radicais após a leitura da matéria.

\footnotetext{
* U ma versão mais extensa dos resultados desse estudo será publicada na revista Science Communication (cf. M acedo et alii, "Effects of online reading on popular science comprehension", in press).
} 
Pós-teste: 0 pós-teste (questionário aplicado após a leitura) media cinco variáveis: percepção da carga cognitiva (oito itens em uma escala Likert-type de cinco pontos), satisfação com o texto (quatro itens em uma escala Likert-type de cinco pontos), compreensão do material, percepção da importância dos documentos (classificação de cada documento em uma escala Likert-type de cinco pontos), estimativa de atenção aos documentos (idem). A compreensão foi medida por meio de 17 questões de múltipla escolha, sendo oito sobre o texto da reportagem e nove especificamente sobre os documentos complementares. Exemplos dessas questões: "Qual a porcentagem de abortos naturais na espécie humana?"; "A mifepristona é considerada mais eficaz para 0 aborto porque...".

Procedimentos: a experiência comportava duas seções de trabalho separadas pelo intervalo de uma semana. As seções aconteciam durante o horário de aula dos estudantes. A primeira foi dedicada ao préteste, e a segunda, à leitura da matéria e ao pós-teste. $0 \mathrm{~s}$ participantes foram divididos em três grupos cuja composição era equilibrada por sexo, experiência com a tecnologia e conhecimentos iniciais do tema. 0 grupo 1 (G 1) leu a matéria na versão hipertexto e, em seguida, respondeu ao questionário de pós-teste. 0 grupo $2(\mathrm{G} 2)$ leu a matéria na versão papel e respondeu ao pós-teste. 0 grupo controle $(G 3)$ respondeu primeiramente às questões de compreensão do pós-teste, em seguida leu 0 texto na versão papel e, ao final, respondeu às demais questões do pós-teste (carga cognitiva, satisfação e atenção). G 1 e G2 foram informados de que teriam 30 minutos para ler a matéria e que, em seguida, deveriam responder a um questionário sobre sua percepção da matéria e sua compreen são das informações. $\mathrm{G} 3$ recebeu a orientação de responder primeiro às questões de compreensão a partir de seus conhecimentos do tema e, em seguida, de ler a matéria (versão papel) e responder às outras questões. Eles tinham 15 minutos para responder ao primeiro grupo de questões e 30 minutos para ler a matéria e responder ao segundo grupo de questões. Todos os participantes foram avisados de que a matéria continha muitas informações e documentos e que, dada a restrição de tempo, teriam de se concentrar sobre alguns documentos - aqueles que lhes parecessem mais importantes.

Ci. Inf., Brasília, v. 32, n. 3, p. 103-112, set./dez. 2003

\section{Resultados}

A presentamos, a seguir, os principais resultados da experiência:

\section{C ompreensão do conteúdo}

A figura 1 mostra a pontuação média de cada grupo nas questões de compreensão sobre a reportagem e os documentos. 0 nível de compreensão do grupo 3 (controle) é bem baixo ( $15 \%$ de respostas certas em média), enquanto 0 dos grupos 1 (hipertexto) e 2 (papel) é satisfatório (63\% e $72 \%$, respectivamente). Além disso, a pontuação do grupo hipertexto na compreensão dos documentos é mais baixa que a do grupo papel.

U ma análise da variância tendo "grupo" (hipertexto, papel, controle) e "tipo de questão" (reportagem e documentos) como fator sistemático e "participantes" como fator aleatório mostra que o nível de compreensão varia significativamente de acordo com a condição experimental $(E(2,44)=72,27)$. 0 s grupos 1 e 2 obtiveram resultados superiores ao grupo $3(E(1,30)=105,38$ e $\underline{F}(1,29)=117,62$, respectivamente), mas $n a ̃ o$ se diferenciaram entre si $(E(1,29)=2,70, n s)$.

A análise da variância mostra também um efeito significativo do tipo de questão $(\underline{F}(1,44)=27,20)$. As questões sobre os documentos tiveram, em média, menos respostas corretas que as questões sobre a reportagem. A demais, encontramos uma interação entre grupo e tipo de questões $(E(2,44)=11,21)$. 0 grupo 1 (hipertexto) teve pontuação mais baixa que o grupo 2 (papel) no questionário sobre os documentos $(47 \%$ e $68 \%$, respectivamente, $E(1,29)=8,01)$. Entretanto, os grupos 1 e 2 obtiveram pontuação semelhante nas questões sobre a reportagem $(80 \%$ e $70 \%$, respectivamente, $\mathrm{E}<1)$. 


\section{Legibilidade de revistas eletrônicas de divulgação científica}

\section{Percepção da carga cognitiva e satisfação}

Constatamos, no conjunto, que a percepção da carga cognitiva foi bem baixa (entre $20 \%$ e $40 \%$ ), enquanto a satisfação foi elevada. A análise da variância mostrou, entretanto, que a condição de apresentação teve um efeito significativo sobre a percepção de carga $(\mathrm{F}(2,44)=6,99)$. 0 grupo 1 (hipertexto) indicou níveis de carga cognitiva significativamente superiores ao grupo 2 (papel) $(\underline{F}(1,29)=7,04)$ e ao grupo 3 (controle) $(\underline{F}(1,30)=11,31)$. No entanto, estes dois últimos grupos não se distinguem significativamente $(\mathrm{F}<1)$.

O s três grupos não apresentaram diferenças na escala de satisfação $(\mathrm{F}<1)$. O s estudantes deram, em geral, respostas muito positivas sobre o conteúdo e o estilo gráfico da matéria. Essas notas não foram significativamente inferiores no grupo hipertexto.

No grupo 1 (hipertexto), o item que representou maior carga foi o gráfico "Q uando começa a vida". N esse grupo, $75 \%$ dos participantes concordaram com a proposição de que era difícil ler as informações do gráfico. No hipertexto, o gráfico era apresentado com uma animação em Flash e os dados de texto eram afixados em letras minúsculas na tela. Para lêlos, era preciso acionar o zoom por meio do botão direito do mouse e, em seguida, deslocar o texto para enquadrá-lo na janela, que ocupava cerca de um terço da tela. No grupo 2 (papel), apenas $27 \%$ dos participantes concordaram com a proposição, embora o gráfico também esteja entre os itens que representaram maior carga nesse grupo. No grupo 3 (controle), 38\% dos participantes concordaram com a proposição. A infografia é, aparentemente, a principal fonte de carga para os leitores do hipertexto.

\section{Discussão}

Os resultados de nossa experiência mostram efeitos negativos do hipertexto para a compreensão de um texto multidocumental, particularmente no que se refere aos documentos secundários, estruturados em menu (neste caso, não-hierárquico, sem indicações de fonte). A compreensão da reportagem foi equivalente entre as condições papel e hipertexto. Poderíamos supor que isto se deve ao fato de os leitores do hipertexto terem passado mais tempo nesse texto, em detrimento dos documentos secundários, compensando a menor legibilidade da reportagem relativamente ao papel. No entanto, as respostas sobre a atenção dispensada aos documentos não confirmam esta hipótese. Tanto os leitores da condição papel quanto os da condição hipertexto disseram ter lido atentamente a reportagem.
Ainda assim, a significativa redução de compreensão dos documentos secundários na condição hipertexto é um claro indício desfavorável para esse meio. Ele parece estar diretamente relacionado com o esforço demandado dos leitores para ler e consultar os documentos, especialmente no que se refere a gráficos e tabelas. Isto poderia indicar que não é recomendável incluir em um hipertexto de textos longos (que demanda tempo de leitura e atenção para ser compreendido), gráficos e ilustrações muito detal hadas ou com animações. Poderia indicar, ainda, que dispor os textos em menu (pelo menos quando este não dá indicações sobre o conteúdo dos links) não é uma boa opção e que, talvez, manter a infografia junto ao texto principal auxilie o leitor a correlacionar os conteúdos.

U m aspecto metodológico relevado na experiência é que "carga cognitiva" e "satisfação" não são necessariamente medidas diretamente proporcionais. Em nosso caso, a satisfação indicada pelos leitores foi alta em todas as condições, enquanto a carga foi menor, com diferenças significativas entre os grupos. Desse modo, pesquisas de opinião baseadas na satisfação dos leitores com 0 texto/ publicação podem esconder problemas de carga cognitiva que os itens de satisfação não permitem revelar. Seria indicado, portanto, que toda pesquisa visando a avaliar o grau de legibilidade de um texto/ hipertexto aferisse a carga cognitiva (ou percepção da carga cognitiva), sem excluir a satisfação.

\section{ONCLUSÕ ES}

0 potencial das tecnologias hipermídia para a divulgação científica esbarra nas exigências de legibilidade dessas tecnologias. Os resultados de nossa pesquisa mostram que a legibilidade dos hipertextos de revistas de divulgação científica é, em geral, medíocre. $N$ enhum dos hipertextos analisados responde de maneira satisfatória às recomendações tiradas de pesquisas experimentais. Os principais problemas se encontram na estruturação dos men us hipertextuais, que não representam de maneira apropriada as características dos documentos e das fontes, bem como as relações entre eles. A navegação entre os documentos, por sua vez, é mais adequada, devido à baixa multilinearidade que esses hipertextos apresentam, mas a falta de informações sobre os links torna difícil saber "o que há por trás" deles e pode perturbar a navegação, já que o leitor tem de fazer inferências a partir de indícios parcos e tênues. Ademais, a falta de ferramentas de manipulação do texto não permite compensar os problemas de navegação. 


\section{Mônica M acedo-Rouet}

A maior parte desses problemas parece ser fruto da pouca atenção/ importância dispensada às versões on-line das revistas. Alguns deles, porém, podem ser decorrentes de escolhas conscientes (por exemplo, nomear o texto de apresentação "introdução"), visando a chamar atenção do leitor para determinados pontos da matéria. A seleção de palavras-chave ou expressões que, no menu hipertextual, identificam os textos da matéria mereceria um estudo complementar para verificar se existe alguma regularidade nessas escolhas e quais os critérios utilizados.

Contudo, é pouco provável que o hipertexto conduza a interpretações radicalmente diferentes dos argumentos difundidos nas matérias. As analogias e os argumentos de autoridade, que são freqüentes nessas matérias e importantes para determinar seus sentidos e conduzir a uma interpretação, não desaparecem nem se modificam de maneira radical no hipertexto. Além disso, o fato de 0 hipertexto fragmentar 0 texto e estabelecer ligações diversas entre os elementos, através dos links associativos, pode criar problemas de coesão e coerência, demandando grande atenção dos autores/ conceptores para com esses mecanismos. U ma limitação deste estudo é que ele não fornece uma comparação sistemática dos mecanismos argumentativos de texto e hipertexto. Porém, reconhecemos a importância dessa pesquisa e, mais geralmente, do estudo de uma retórica "própria" ao hipertexto. Entretanto, mostramos que 0 hipertexto pode levar a dificuldades de leitura e de compreensão dos argumentos em razão das más condições de legibilidade.

Essa hipótese foi verificada em um estudo experimental de leitura de uma das matérias do corpus: "A pílula da discórdia", revista Superinteressante. O s resultados de nossa experiência mostraram efeitos negativos do hipertexto para a compreensão da matéria, particularmente dos documentos secun dários, estruturados em forma demenu de informações. A redução significativa da compreensão desses documentos na condição hipertexto é um claro indício desfavorável para esse suporte. Esta redução parece estar diretamente relacionada ao esforço necessário à leitura e à consulta dos documentos no meio eletrônico, sobretudo no que diz respeito aos gráficos e tabelas. I sso sugere que não é adequado incluir, em um hipertexto de textos longos, gráficos e ilustrações muito detalhadas ou com animações. E também que dispor os textos em menu não é uma boa opção (pelo men os quando o menu é pobre em informações sobre os links). Integrar a infografia no texto principal é provavelmente melhor para ajudar o leitor a relacionar os conteúdos.
A pesar dos resultados negativos na compreensão dos documentos secundários e da percepção de carga cognitiva mais forte nos leitores do hipertexto, os participantes deram mostras de al guma f lexibilidade, pois se adaptaram ao suporte sem rejeitá-lo globalmente. A satisfação ante o hipertexto é comparável com a observada diante do papel. 0 u seja, não háa priori rejeição ao hipertexto e à tecnologia, mas os usuários experimentam dificuldades no momento de ler e compreender uma matéria multidocumental complexa sobre o suporte digital.

O s resultados da análise das matérias e da experiência de leitura mostram, no que concerne às estratégias de elaboração de revistas on-line de divulgação científica, que é possível apresentar os conteúdos sob forma eletrônica. 0 suporte não se opõe per se à argumentação da divulgação, e os usuários não demonstram nenhuma rejeição da tecnologia. M as, para atrair um leitorado, essas revistas deverão de ter um cuidado especial com a qualidade da legibilidade dos hipertextos. A produção de hipertextos legíveis e compreensíveis poderia abrir um mercado importante para as revistas, à medida que as escolas e universidades coloquem equipamentos mais sofisticados à disposição dos alunos.

Os fatores implicados na utilização das tecnologias hipermídia para a divulgação científica são diversos e ainda mal compreendidos. Entre a argumentação da divulgação, as estratégias editoriais das revistas, a legibilidade dos hipertextos e a compreensão há certamente uma relação, mas o vínculo entre esses componentes ainda não está bem estabelecido. Esta pesquisa sublinha a complexidade do problema e mostra a necessidade e 0 interesse de se construírem instrumentos teóricos mais desenvolvidos para o estudo do tema. Tal pesquisa pode, ainda, levar-nos a conceber hipertextos mais legíveis e eficazes, além de melhorar nossos conhecimentos sobre a própria estrutura do texto escrito, o que representa um interesse teórico e pedagógico certo e durável.

\section{AGRADECIMENTOS}

Parte desta pesquisa foi financiada pela $C$ apes, por meio de uma bolsa de doutorado sanduíche. A gradeço a Isaac Epstein e a Pierre Fayard, pela orientação, e a JeanFrançois Rouet, pela realização das estatísticas do estudo experimental e pelos comentários e sugestões. 


\section{Legibilidade de revistas eletrônicas de divulgação científica}

\section{REFERÊN CIAS}

BALPE, J. P. et al. Techniques avancées pour I'hypertexte. Paris: Hermes, 1996.

BAUER, M. La longue durée of popular science, 1830 - present. In: D evèze-Berthet. $(E d$.$) . La promotion de la culture scientifique. Paris : PU F,$ 1996. p. 75-92.

BEAU GRAN DE, R. DE . N ew foundations for a science of text and discourse: cognition, communication and the freedom of acess to knowledge and society. New Jersey: Ablex Publishing, 1997.

BOLTER, J. D. W riting space: the computer, hypertext and the history of writing. [S. I.] : Lawrence Erlbaum, 1991.

BRETON, P. L'argumentation dans la communication. Paris : La D écouverte, 1996. (Repères, 204).

BRITT, M. A.; ROUET, J.-F.; PERFETTI, C. A. U sing hypertext to study and reason about historical evidence. In: ROUET, J. F. et al. (Ed.). H ypertext and cognition. [S. I.] : Lawrence Erlbaum, 1996. p. 4372 .

BU SH, V. (1945). As we may think. Atlantic M onthly, 1945. Disponível em: <http :/ / www.isg.sfu.ca/ duchier/ misc/ vbush/ vbush-all.shtm>. A cesso em: 07 jul. 2001.

CARO, S.; BÉTRANCOURT, M. Ergonomie des documents techniques informatisés: expériences et recommendations sur I'utilisation des organisateurs para-linguistiques. In: TRICOT, A. ROUET, J.-F. (O rg.). Les hypermédias: approches cognitives et ergonomiques. Paris: Hermès, 1998.

CHARNEY, D. The impact of hypertext on processes of reading and writing. In: HILLIGOSS, S.; SELFE, C. (Ed.). Literacy and computers. New York: M LA., 1991

CHEN, C.; RADA, R. Interacting with hypertext : a meta-analysis of experimental studies. Human-Computer Interaction, n. 11, p. 125-156, 1996.

DEE-LUCAS, D. Effects of overview structure on study strategies and text representation for instructional hypertexte. In: ROUET, J.-F. et al. (Ed.). H ypertext and cognition. [S. I.] : Lawrence Erlbaum, 1996, p. 73107.

DILLON, A. ; GABBARD, R. Hypermedia as an educational technology: a review of the quantitative research literature on learner comprehension, control and style. Review of Educational Research, v. 68, n. 3, p. 322-349, 1998.

ENGELBART, D. A conceptual framework for the augmentation of man's intellect. In: HOWERTON, WEEKS. (Ed.). V istas in Information handling. W ashington: Spartan Books, 1963. p. 1-29.

EVELAND, W. P. ; DUNWOODY, S. U sers and navigation patterns of a science world wide web site for the public. Public U nderstanding of Science, v. 7, n. 4, p. 285-311, 1998.

EVELAND, W. P. ; DUNWOODY, S. U ser control and structural isomorphism or disorientation and cognitive load? Learning from the web versus print. Communication Research, v. 28 , n. 1, p. 48-78, Feb. 2001.
FRIEDMAN， S. M.; DUNWOODY, S.; ROGERS, C. (Ed.). Communicating uncertainty: media coverage of new and controversial science. [S. I.] : Lawrence Erlbaum, 1999.

GLEAVES, R. Learning from books: eight design principles for instructional hypermedia. [S. I.] : San Diego State U niversity, 1998. Disponível em: <http :// et.sdsu.edu/rgleaves/ ET640.htm>. A cesso em: 28 ago. 2001.

HOUSE OF THE LORDS (London). Science and society. London : Her M ajesty's Stationary O ffice, 2000.

KOCH, I. G. V. A rgumentação e linguagem. São Paulo: Cortez, 1996.

LAN D OW, G. H ypertext 2.0. Baltimore: Johns Hopkins U niversity, 1997.

LÉVY, P. C yberculture. Paris : O dile Jacob, 1997.

M ILLER, S. Public understanding of science at the crossroads. Public Understanding of Science, n. 10, p. 115-120, 2001.

NELSON, T. Literary machines. Swathmore, PA : Self-published, 1981.

NIELSEN, J. Designing web usability. Indianapolis: New Riders Publishing, 2000.

PALÁCIOS, M. Hipertexto, fechamento e o uso do conceito de nãolinearidade discursiva. In: CONGRESSO ANUAL DA COMPOS, 1998. Anais... [S. I. : S. n. ], 1998.

PETERSO N, I. Touring the scientific web. Science Communication, v. 22, n. 3, p. 246-255, 2001.

ROUET, J.F. Les activités documentaires complexes: aspects cognitifs et développementaux. Poitiers : U niversité de Poitiers, 2001. (Rapport d'H abilitation à Diriger des Recherches).

SCHNOTZ, W. Sign systems, technologies, and the acquisition of knowledge. In : ROUET, J. F.; LEVONEN, J.; BIARDEAU, A. M ultimedia learning: cognitive and instructional issues. [S. I] : Elsevier, p. 9-29, 2001.

TEW KSBU RY, D. ; ALTHAUS, S. Print vs. on line news. Journalism \& M ass Communication Q uaterly, Jan. 2001.

TRENCH, B. Science journalism on the web. In: SEMINAIRE SUR LES NOUVEAUX TERRITORIES DE LA COMMUNICATION SCIENTIFIQUE, 2000, Paris. [S. I. : s. n.], 2000.

TRUMBO, C. et al. U se of e-mail and the web by science writers. Science Communication, v. 22, n. 4, p. 347-378, 2001.

VIGNAUX, G. L'argumentation du discours à la pensée. Paris: Hatier, 1999. (Collection optiques philosophie).

VAN OOSTENDORP, H. ; VAN NIM WEGEN, C. Locating information in an online newspaper. Journal of $C$ omputer $M$ ediated $C$ ommunication, $v$. 4, n. 1, 1998. Disponível em: <http :// www.ascusc.org/ jcmc/ vol4/ issuel/ oostendorp.html>. A cesso em: 20 fev. 2001. 